\title{
Case: Spontaneous regression of post-radical prostatectomy prostate-specific antigen elevation without adjuvant therapy in a patient with lymph node metastasis
}

\author{
Taehyoung Lee, MD; Yanbo Guo, MD; Saahil Vij, MD; Rahul Bansal, MD; Nathan C. Wong, MD; \\ Bobby Shayegan, $M D$
}

Department of Surgery, Division of Urology, McMaster University, Hamilton ON, Canada

Cite as: Can Urol Assoc J 2017;11 (7):E315-7. http://dx.doi.org/10.5489/cuaj.4324 Published online July 11, 2017

\section{Abstract}

Prostate cancer remains the most frequently diagnosed cancer among men. The combination of clinical stage, serum prostatespecific antigen (PSA), and Gleason score (biopsy) assists in predictive assessment of pathological stage and prognosis. Furthermore, pathological criteria, including Gleason score, surgical margin status, extracapsular extension, seminal vesicle invasion, and lymph node involvement, provide prognostication in patients undergoing radical prostatectomy $(\mathrm{RP})$. In this paper, we present a case of a patient with high-risk prostate cancer with persistent PSA elevation post-RP who experiences a complete regression of PSA without any adjuvant therapy. To the authors' knowledge, such a finding has not been described in the literature previously.

\section{Introduction}

Prostate cancer continues to be the most common noncutaneous malignancy in U.S. men. ${ }^{1}$ It is estimated that one in six men will be diagnosed with prostate cancer in their lifetime. ${ }^{2}$ With the initiation of prostate cancer screening, the majority of prostate cancer is treated at the local or locally advanced stage. Radical prostatectomy (RP) is one of the most common treatment modalities for localized prostate cancer; however, despite improvements in surgical technique, $2541 \%$ of men will develop prostate-specific antigen (PSA) recurrence within 10 years after surgery. ${ }^{3}$ While a significant portion of these men do not develop to clinical progression, those that develop into metastatic disease have a median time of death of less than five years. ${ }^{4}$ Factors that increase mortality include PSA doubling time, pathological Gleason score, advanced tumour stage, and time from surgery to biochemical recurrence (BCR). ${ }^{5}$ Current treatments for BCR include androgen-deprivation therapy and salvage radiation therapy.
Spontaneous regression of cancers is a rare occurrence. Regression of regionally metastatic prostate cancer has been rarely reported in literature. A review by Challis et al examined a period of 87 years in which there were no reported cases of prostate cancer remission. ${ }^{6}$ We present a case of a patient with high-risk prostate cancer with persistent PSA elevation post-RP who experiences a complete regression of PSA without any second-line therapy.

\section{Case report}

A 65-year-old asymptomatic retired surgeon presented with an elevated PSA of $30.85 \mathrm{ug} / \mathrm{L}$. He had a previous history of hypertension, hypercholesterolemia, and mild osteopenia. He was treated in the past for prostatitis with a serum PSA level of $16 \mathrm{ug} / \mathrm{L}$ and was subsequently lost to followup. In August 2009, the 65-year-old presented back with an elevated PSA of $30.85 \mathrm{ug} / \mathrm{L}$. Subsequent transrectal ultrasound-guided biopsy revealed a Gleason $8(4+4)$ adenocarcinoma with positive cores in right base (50\%) and left base (5\%). Staging computed tomography (CT) scan also revealed a large $2.8 \mathrm{x}$ $2.1 \mathrm{~cm}$ lymph node medial to the left external iliac artery.

In lieu of his advanced disease, he was given one injection of goserelin in conjunction with oral bicalutamide. An ultrasound-guided biopsy of the left external iliac node revealed reactive lymph node with histiocytosis, fibrosis, reactive granulation tissue, and hyalinization with no evidence of overt malignancy. Treatment options were thoroughly discussed with the patient, including continued androgen-deprivation therapy, external beam radiation therapy with neoadjuvant/concurrent/adjuvant hormones, and RP with pelvic lymph node dissection. The patient elected to undergo a retropubic RP with extended pelvic lymph node dissection. The procedure and postoperative course were uncomplicated. Final pathology revealed adenocarcinoma, Gleason $9(5+4)$ involving $5 \%$ of tissue with bilateral seminal vesicle involvement (T3b) and evidence of perineural invasion. One (left iliac node) out of 34 lymph 
Lee et al.

nodes was positive for tumour involvement. The surgical margins were negative.

However, his six-week postoperative PSA was 2.06 ug/L. Bone scan was negative for metastatic disease, but contrastenhanced CT chest/abdomen/pelvis revealed a new, suspicious $2.4 \mathrm{~cm}$ lymph node adjacent to left internal iliac artery. His PSA was monitored closely and, as was expected from his high-risk pathology, there was a very gradual rise in his PSA level over the next two years (2.27 ug/L in June 2010, $2.38 \mathrm{ug} / \mathrm{L}$ in September 2010, $3.34 \mathrm{ug} / \mathrm{L}$ in January 2011, $3.85 \mathrm{ug} / \mathrm{L}$ in April 2011, and $3.86 \mathrm{ug} / \mathrm{L}$ in August 2011) (Fig. 1). Given his slow PSA doubling time, asymptomatic status, and relatively low PSA level, the decision to start him on androgen-deprivation or salvage radiation was deferred, but continually reviewed at every followup visit. Interestingly, two years after his prostatectomy, his PSA spontaneously became undetectable $(<0.04 \mathrm{ug} / \mathrm{L}$, confirmed on repeat testing). His testosterone was measured to be within normal limits at $12.1 \mathrm{nmol} / \mathrm{L}$. He continued to exhibit undetectable PSA level with normal serum testosterone level. A repeat $\mathrm{CT}$ chest/abdomen/pelvis revealed decreased size in the left internal iliac node from $2.3 \times 2.4 \mathrm{~cm}$ to $1.4 \times 1.0 \mathrm{~cm}$ (Fig. 2). He has not received any adjuvant therapy since his $\mathrm{RP}$ and he remains in complete biochemical remission, with the most recent PSA of $<0.02 \mathrm{ug} / \mathrm{L}$ four years postoperatively.

\section{Discussion}

Despite the stage migration associated with PSA testing and the increasing number of organ-confined disease, at least 10\% of men with newly diagnosed prostate cancer have locally advanced disease. High serum PSA, high Gleason grade, evidence of seminal vesicle involvement, or lymph node metastases are among features that indicate high-risk disease and

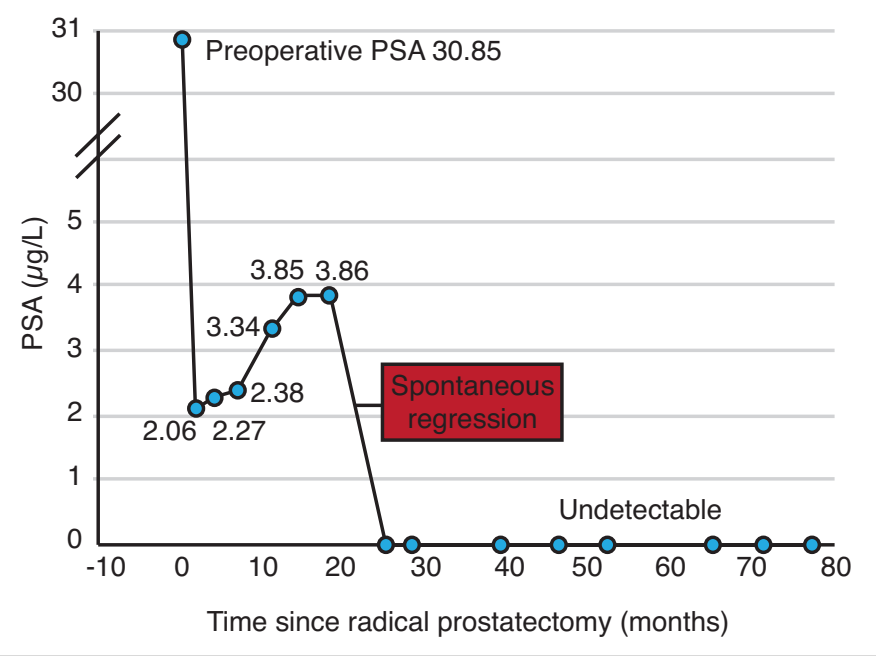

Fig. 1. Prostate-specific antigen (PSA) measurements pre- and post-radical prostatectomy. Sustained biochemical regression of initially elevated PSA post-radical prostatectomy. predict worse oncological outcome. Patients with evidence of seminal vesicle invasion or lymph node metastases are highly likely to develop clinical progression (86\% and 95\%, respectively) after RP. ${ }^{7}$ In a long-term study of 1000 patients undergoing RP, Hull et al reported five-year biochemical recurrencefree survival of $37 \%$ and $18 \%$ for men with seminal vesicle invasion and lymph node metastases, respectively. ${ }^{8}$

We present a case of a patient with clinical high-risk features (high serum PSA and Gleason $4+4$ disease on biopsy, pelvic lymph node on $\mathrm{CT}$ ), as well as pathological high-risk features (Gleason $5+4$, bilateral seminal vesicle invasion, lymph node metastases, and detectable PSA post-RP). Our prognostic prediction would have suggested extreme likelihood of biochemical and clinical progression of his prostate cancer, requiring a number of adjuvant/salvage therapeutic options, potentially causing treatment-related toxicities. Against many odds, the patient not only achieved clinical remission, but has achieved complete biochemical spontaneous regression of an elevated PSA post-RP without any adjuvant therapy. This is evidenced by persistently undetectable PSA level in the context of normal serum testosterone.

Spontaneous regression of other genitourinary malignancy, such as renal cell carcinoma, has rarely been described, usually involving regression of pulmonary metastasis after removal of the primary tumour. ${ }^{9}$ Spontaneous regression of primary renal cell carcinoma with inferior vena cava (IVC) tumour thrombus has also been described. ${ }^{10}$ To our knowledge, such spontaneous regressions have not been previously described in prostate cancer literature. The rarity of this particular case does not allow for physiological analysis of the curative mechanisms at play, but serves to highlight the importance of continued surveillance in the lymph nodepositive subset of patients.

Competing interests: The authors report no competing personal or financial interests.

This paper has been peer-reviewed.

\section{References}

1. Siegel R, Ma J, Zou Z, et al. Cancer statistics, 2014. CA Cancer J Clin 2014;64:9-29. https://doi.org/10.3322/caac.21208

2. Brawley 0. Trends in prostate cancer in the United States. J Natl Cancer Inst Monogr 2012;45:152-6. https://doi.org/10.1093/incimonographs/lgs035

3. Lee EK, Thrasher JB. Management of biochemical recurrence after definitive therapy for prostate cancer. Campbell-Walsh Urology 11th edition Wein A, Kavoussi L, Partin A et al. Philadelphia: Elsevier. 2016;119:2770.

4. Pound CR, Partin AW, Eisenberger MA, et al. Natural history of progression after PSA elevation following radical prostatectomy. JAMA 1999;281:1591-7. https://doi.org/10.1001/jama.281.17.1591

5. Boorijan SA, Karnes RJ, Crispen PL, et al. Radiation therapy after radical prostatectomy: Impact on metastasis and survival. J Urol 2009;182:2708-14. https://doi.org/10.1016/i.juro.2009.08.027

6. Challis GB, Stam HJ. The spontaneous regression of cancer: A review of cases from 1900 to 1987. Acto Oncologica 1990;29:545-50. https://doi.org/10.3109/02841869009090048 


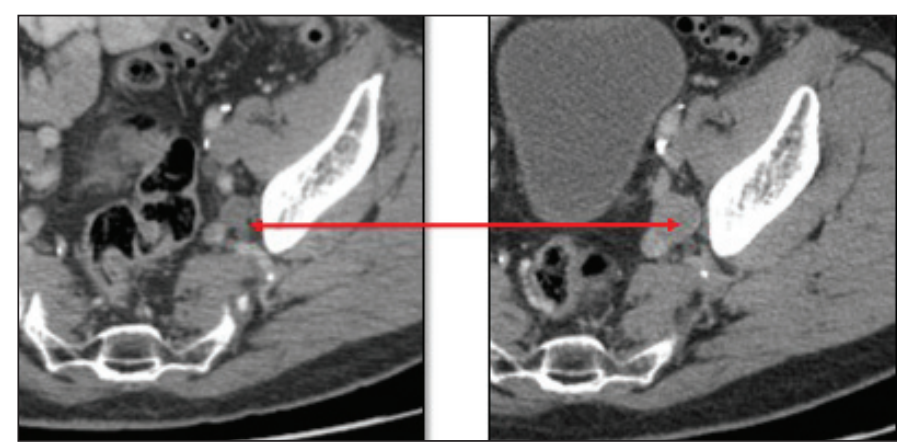

Fig. 2. Spontaneous decrease in size of left internal iliac node from $2.3 \times 2.4$ $\mathrm{cm}$ (three months postoperatively) to $1.4 \times 1.0 \mathrm{~cm}$ (two years postoperatively) without adjuvant treatment.
7. Meng M, Carroll P. Treatment of locally advanced prostate cancer. Campbell-Walsh Urology 11 th edition. Wein A, Kavoussi L, Partin A et al. Philadelphia: Elsevier. 3;118:2757-8 (2016).

8. Hull G, Rabbani F, Abbas F, et al. Cancer control with radical prostatectomy alone in 1000 consecutive patients. J Urol 2002;167:528-34. https://doi.org/10.1016/S0022-5347(01)69079-7

9. Edwards $M$, Anderson J, Angel J, et al. Spontaneous regression of primary and metastatic renal cell carcinoma. J Urol 1996;155:1385. https://doi.org/10.1016/S0022-5347(01)66275-X

10. Kobayashi K, Sato T, Sunaoshi K, et al. Spontaneous regression of primary renal cell carcinoma with inferior vena cava tumour thrombus. J Urol 2002;167:242-3. https://doi.org/10.1016/S0022$5347(05) 65424-9$

Correspondence: Dr. Yanbo Guo, McMaster University, Hamilton ON, Canada; yanbo.guo@medportal.ca 